\title{
10 AÑOS DE UNA PERFORMANCE FLAMENCA: MORENTE Y SONIC YOUTH EN EL CA2M
}

\author{
MARÍA JOSÉ JIMÉNEZ PÉREZ \\ Universidad de Granada
}

Resumen

El año 2010 fue significativo para el flamenco: entraba a formar parte de la Lista Representativa del Patrimonio Cultural Inmaterial de la UNESCO y cerraba un episodio esencial con la muerte de Enrique Morente, quien el 2 de febrero nos legaría un hecho singular al protagonizar, junto a dos miembros de Sonic Youth, una performance inusual en el Centro de Arte 2 de mayo de Móstoles, donde flamenco "primitivo" y Nuevo Flamenco dialogan con el rock experimental de la banda neoyorquina.

\section{Palabras clave}

Postmodernidad; flamenco; arte conceptual; fluxus; performance; música experimental.

\section{YEARS SINCE A FLAMENCO PERFORMANCE: MORENTE AND SONIC YOUTH AT THE CA2M}

\section{Abstract}

The year 2010 was significant for flamenco: it enters at the Representative List of Intangible Cultural Heritage and Enrique Morente dies. Besides, we should add a singular fact, Morente performed with two members of Sonic Youth, on 2 of February, an unusual performance at the Art Center May 2 of Mostoles, where "primitive" flamenco and new flamenco dialogue with the experimental rock band from New York.

\section{Keywords}

Postmodernism; flamenco; conceptual art; fluxus; performance; experimental music. 


\section{Introducción}

La performance realizada por Enrique Morente y Sonic Youth en el Centro de Arte Contemporáneo 2 de mayo de Móstoles el 2 de febrero de $2010^{1}$, constituye nuestro objeto de estudio, que abundará en su carácter de performance sonora y en la convergencia de estilos musicales y artísticos que presenta.

Para abordar nuestro objeto de estudio desde su naturaleza de performance sonora, profundizamos en lo que supuso el Nuevo Flamenco y en la significación de movimientos artísticos ligados a las performances sonoras como el arte conceptual, fluxus y el grupo musical de vanguardia español ZAJ. Del mismo modo, trataremos los recorridos individuales de Enrique Morente -y la importancia de Omega- y del grupo neoyorquino Sonic Youth -y la importancia de los colectivos de artistas como paradigmas de la escena underground-.

La performance de Morente y Sonic Youth, heredera de los movimientos citados, se produce también en el contexto de la hibridación transcultural, que ya era propia del Nuevo Flamenco y que es definitoria del contexto de la Posmodernidad ${ }^{2}$. La hibridación transcultural tiene la capacidad de crear nuevas realidades más complejas a partir de la fusión de distintas culturas (Rogers, 2006, pág. 477), para lo que es necesario la modificación de las distintas culturas que convergen en el nuevo fenómeno (González Alcantud \& Lorente Rivas, 2004). En este sentido podemos concluir que en nuestro objeto de estudio se fusionan dos géneros musicales propios de dos culturas distintas: de un lado, el rock -y la experimentación de Sonic Youth- y, de otro, el flamenco -y la experimentación de Morente-, que forman una nueva realidad, producto también de la renovación en el flamenco que impulsó Enrique Morente y de la constante interdisciplinariedad de artes y búsqueda de nuevos discursos.

\section{Antecedentes. Nuevo flamenco y flamenco posmoderno}

En términos generales, se entiende como Nuevo Flamenco una corriente alejada de la purista, si bien, fue una etiqueta comercial usada a principios de 1980 para definir la producción de jóvenes flamencos ${ }^{3}$. Paco de Lucía, Camarón y Morente, entre otros, estuvieron en la nómina del Nuevo Flamenco y, aunque tuviesen trabajos dentro de la vertiente purista, realizaron otros donde fusionaban el flamenco con otras músicas, lo que llevó al Nuevo Flamenco más allá de ser una etiqueta comercial.

En lo referido a lo comercial, funcionó para vender un producto "nuevo", pero las fusiones pertenecían a un contexto posmoderno en el que el mundo se había abierto económica y culturalmente y, en ese sentido, sería conveniente tratar a ese nuevo flamenco dentro del "flamenco posmoderno". Así, el flamenco posmoderno se manifiesta bajo los parámetros de la cultura posmoderna (Steingress, Nuevo flamenco e hibridación transcultural: una aproximación socio-musicológica, 2007) y ha de estudiarse dentro del marco teórico de la hibridación transcultural.

Desde la década de 1950 las fusiones se han vuelto constantes en el flamenco no purista debido a un cambio en el comportamiento musical en función del mercado y el gusto del público (Steingress, La hibridación transcultural como clave de la formación del Nuevo Flamenco, 2007). Steingress establece una periodización y tendencias de la fusión flamenca:

1) Jazz y flamenco fusión

1.1) $1956-1966$

Los músicos de jazz descubren el flamenco y lo toman como enriquecimiento de sus composiciones. Ejemplos de esta primera etapa son los trabajos de Miles Davis y Gil Evans Flamenco Sketches (1956) y Miles Ahead (1957); Olé de John Coltrane (1961); y Jazz. Flamenco

\footnotetext{
${ }^{1}$ Véase: https://www.youtube.com/watch?v=aRQSqZDrBUo, [Consultado el 3 de junio de 2020].

2 Contrapuesta a la Modernidad, la Posmodernidad surge en América en el contexto del capitalismo tardío y se manifiesta también en el contexto artístico a través de formas híbridas generadas por la irrupción de los mass media y las nuevas tecnologías, caso de la performance. En la Posmodernidad se busca el placer inmediato a través de los bienes de consumo y no existe tanta barrera entre cultura culta y cultura popular. Para profundizar en el contexto cultural de la Posmodernidad, véase (Jameson, 1996).

${ }^{3}$ La etiqueta "Jóvenes flamencos" fue propuesta por Mario Pacheco Villarejo para su sello Nuevos Medios, creado en 1982. Véase: (Gamboa, 2011, pág. 95).
} 
(1958), de Lionel Hampton. Esta primera etapa se caracterizaba por la asimilación del flamenco por parte de los jazzistas.

1.2) 1966-1990

Caracterizada por la cooperación entre músicos de jazz y flamencos. Destacan, entre otros, los trabajos de Paco de Lucía y el saxofonista Pedro Iturralde: Flamenco-Jazz (1967) y Jazz-Flamenco II (1968).

2) Rock, rock-andaluz, salsa y rumba

Los años 70 se coronan como la década de mayor proliferación de fusiones. El flamenco y el rock vinieron unidos en múltiples trabajos, siendo prueba "Spanish Caravan", dentro del LP W aiting for the Sun (1968) del grupo The Doors. A raíz de la popularidad del rock y la "fiebre fusionista" surge en 1971 SMASH, definido ya como rock-andaluz ${ }^{4}$. A ellos les siguieron Pata Negra, Triana, Lole y Manuel -que rescatan la aportación árabe-, Kiko Veneno, Las Grecas -que introducen el elemento electrónico- o Medina Azahara. Además del rock y la electrónica, la rumba y la salsa se "mezclaron" con el flamenco, siendo significativos los trabajos de Ketama a partir de 1990.

Pero, sin lugar a dudas, el trabajo que más popularidad adquirió en este tiempo fue el LP La leyenda del Tiempo (1979) de José Monge Cruz, título homónimo al poema que abría el tercer acto de Asi que pasen cinco años que Lorca escribió en 1931 tras su viaje a Nueva York y que Camarón musicalizó para este trabajo -y veinte años más tarde hizo lo propio Morente en su álbum Lorca-. El disco, en cuya portada Camarón quedaba retratado como un roquero y en el que habían colaborado Raimundo Amador y Kiko Veneno, se distanciaba del flamenco neotradicional en la inclusión de nuevos instrumentos como el bajo eléctrico y la flauta. A partir de él surgieron numerosos trabajos de flamenco-fusión, ya dentro de la etiqueta comercial Nuevo Flamenco, que reunían tales instrumentos.

3) Nuevo Flamenco, etiqueta y subgénero

En 1980 la popularidad del flamenco-fusión dio lugar a la formación de un subgénero que tomó el nombre de esta etiqueta comercial y que se producía dentro del denominado flamenco posmoderno -por asimilar principios de la posmodernidad tales como la difusión de los mass media y el proceso de hibridación transcultural-. Pues bien, Nuevo Flamenco y flamenco "viejo" conviven desde entonces. Al respecto, es interesante la opinión de Mairena cuando en 1983, con motivo del primer número de la revista Cabal, Alfredo Grimaldos le pregunta sobre el subgénero:

A. G.: Pero ¿qué piensa de la corriente que puede englobar a Chiquetete, Turronero o Lole y Manuel, ¿entre otros?

A. M.: Todos esos que tú acabas de nombrar, poco se ocupan de buscar flamenco puro; parten del flamenco, pero intentan crear o encontrar las condiciones para que ellos puedan estar en primera línea. Luego, lo que dure ha durado. Y vendrá otra moda que les quite el puesto -sigue, de manera premonitoria- Un caso diferente es el de Enrique Morente, que hace un cante futurista, intentando marcar la línea de lo que puede ser el flamenco de mañana. Puede ser así y no ser, pero al menos trabaja con honestidad. (Gamboa, 2011, pág. 38).

Realmente, dentro de la nueva corriente Morente marcó el camino, ya no tanto en forma, sino en significado. El flamenco no purista era un modo de identificación alternativo, parejo a los principios progresistas de la España posfranquista, que respondía a un cambio general en la sociedad una vez el país se había desprendido del carácter nacionalista propio de la dictadura. Pero el germen de cambio en términos semióticos lo había producido Enrique Morente y lo mantuvo durante toda su trayectoria como veremos en el apartado dedicado al álbum Omega.

\footnotetext{
${ }^{4}$ Para profundizar en este tema son recomendables los estudios de Diego García Peinazo: (Peinazo, Rock andaluz, orientalismos e identidad en la Andalucía de la transición (1975-1982), 2013) y (Peinazo, Prácticas culturales en torno al rock andalur. Entre el imaginario y la nostalgia de Andalucía, 2014).
} 
El arte en/ de la posmodernidad: la primacía del concepto: arte conceptual. La recuperación del ready-made y la contribución de john cage.

David Tudor subió al escenario y se sentó ante el piano [...] Sin embargo, incluso los "hípsters" de Nueva York, tan abiertos de mente, quedaron atónitos y montaron en cólera a raíz de la última composición de Cage, "4’33"”, en la que... no pasaba absolutamente nada. (Gompertz, 2013, pág. 353)

En una síntesis de su praxis, el arte conceptual se caracteriza por la primacía de la idea concepto- sobre el objeto, rompiendo con esto la decimonónica historia de los estilos y cuestionando la historia del arte como historia de percepción visual (Rocca, 2013). Con ello, no solo se produce una ruptura entre obra física y concepto subyacente en un proceso de desmaterialización del objeto artístico, sino que supuso también el punto de inflexión entre modernismo y posmodernismo.

El arte conceptual surge en la década de 1960 bajo una recuperación de las teorías de Marcel Duchamp. En contacto con el círculo dadaísta ${ }^{6}$, Duchamp rechazó la estética tradicional y prefirió elementos y objetos procedentes de la industria que, mediante un cambio del significado utilitario, se convertían en ready-made. El ready-made es un objeto cotidiano fabricado sin intención estética que funciona como objeto artístico por decisión del creador.

Duchamp trajo la idea a un primer plano en Fuente (fig. 1), "creada" bajo el seudónimo de R. Mutt (conocido fabricante de material sanitario) y expuesta en la primera exposición de la Sociedad de Artistas Independientes de Nueva York en 1917, celebrada en el Grand Central Palace (Julián, 2000, pág. 42). Fuente dejaba de ser un urinario en el contexto expositivo y, al estar liberado de su utilidad, actuaba como objeto artístico, cosa que remite a la idea de "arte es todo lo que los hombres llaman arte” (Jiménez, 2004, págs. 17-52), en cuanto a que el artista es quien decide qué es arte.

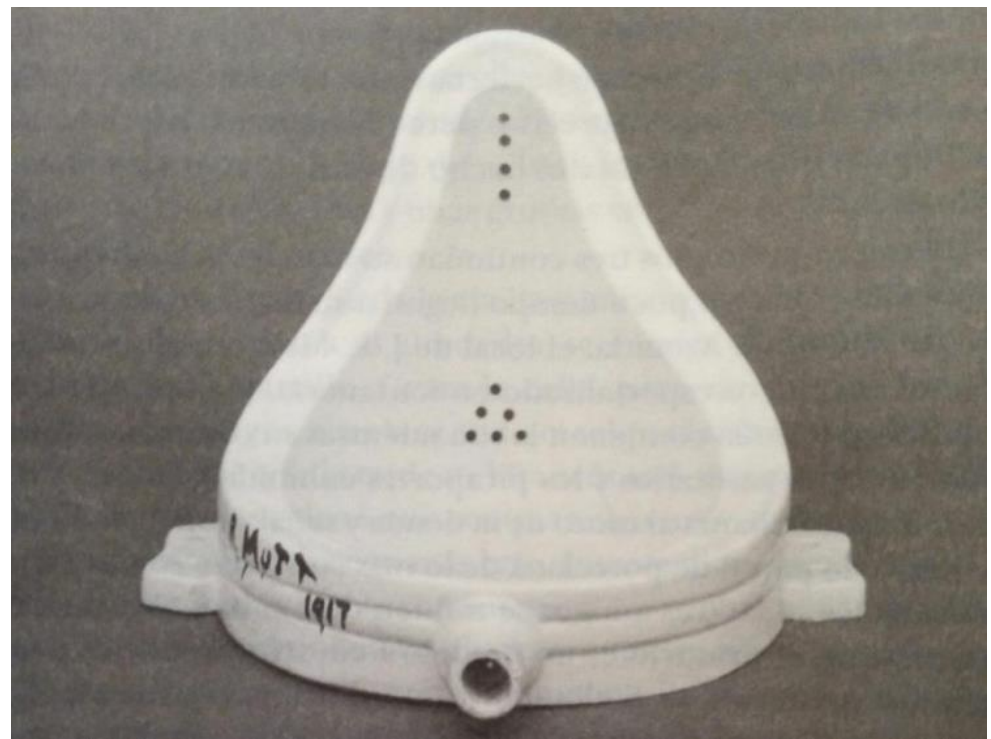

Fig. 1. Fuente. Marcel Duchamp, 1917. Imagen: Will Gompretz, ¿Qué estás mirando? 150 años de arte moderno en un abriry cerrar de ojos. p. 28.

\footnotetext{
${ }^{5}$ Marcel Duchamp (1887-1968) fue un artista francés, creador del ready-made. Establecido en París hasta 1910, la obra de Duchamp está vinculada al impresionismo, fauvismo y cubismo. A partir de 1911 su obra cambia hasta alejarse totalmente de las tendencias artísticas establecidas hasta el momento, prefiriendo los objetos cotidianos procedentes de la industria. A finales de la década de 1910 se establece en Nueva York, introduciendo junto a otros artistas exiliados el movimiento dadá.

${ }^{6}$ El dadaísmo es un movimiento internacional surgido durante la I Guerra Mundial, tras el expresionismo, el futurismo, el cubismo, el suprematismo y la abstracción, desarrollado al tiempo que el neoplasticismo y el constructivismo. Entre los principios del dadá y bajo los parámetros del nihilismo, se encuentran: la no relación entre arte y sociedad y el deseo de no-estilo.
} 
En el desarrollo del arte conceptual mucho tuvo que ver John Cage, compositor experimental estadounidense influenciado por el budismo zen (Gómez, 2009, pág. 239). Cage indagó en los principios del azar y la aleatoriedad -que en su opinión estructuraban el universo- hasta concebir la música como una combinación aleatoria de silencio y sonido ambiental (Foster, 2006, pág. 368). Si bien, antes de abrazar la filosofía oriental, el compositor había creado el "piano preparado" a finales de la década de 1930, en base a otros experimentos de Satie (Gómez, 2009, pág. 242) ${ }^{7}$. El piano preparado consistía en introducir tornillos, tuercas, trozos de goma y madera en el encordado para crear sonidos distintos al habitual -esta búsqueda de distorsión será un elemento fundamental en el contexto del rock experimental neoyorquino-. Cuando Cage conoció a Duchamp en 1942, el compositor comenzó a reflexionar sobre la idea de la no-composición (Foster, 2006, pág. 370).

En 1951 Cage se encierra en una cámara anecoica -insonorizada- y descubre que el silencio absoluto no existe -oía su sistema nervioso y su circulación sanguínea-. En el verano de 1952 Cage participa, junto al pintor Robert Rauschenberg y el coreógrafo Merce Cunningham, en una sonada velada en el Black Mountain College de Carolina del Norte, escuela de arte experimental y multidisciplinar visitada por Cage entre 1948 y 1953. Tal evento supuso un claro precursor del happening y, más tarde, de la performance: mientras Rauschenberg exhibía unos cuadros, Cunningham bailaba y Cage daba una conferencia con partes de silencio absoluto desde unas escaleras (Gompertz, 2013, pág. 352). La simultaneidad de las acciones y la improvisación de los protagonistas, que no tenían un espacio único al que ajustarse, llevó a la creación de otros eventos similares llamados "collages de acciones" o "acontecimientoespectáculo" (Guasch Ferrer \& Hernando Carrasco, 2000, pág. 79).

Por aquel tiempo Cage compuso 4'33", que fue interpretada por David Tudor, su pianista favorito, en el Maverich Concert Hall de Woodstock el 29 de agosto. Tudor "tocó" los tres movimientos (33", 2'40" y 1'20") mediante el cierre de la tapa del piano y su apertura al final de cada movimiento (Walther, 2012, pág. 582). Tras la interpretación, "incluso los hípsters [...] montaron en cólera" porque no había pasado "absolutamente nada". En realidad, sí pasó: el público -la tos y el murmullo de los asistentes- había construido el ruido en el vacío sonoro (Gompertz, 2013, pág. 353).

Con tales hazañas y a la par que enseñaba la teoría del azar y la conjunción sonidos-actos en la New School for Social Research de Nueva York a finales de 1950, a Cage le surgieron seguidores. Uno de ellos fue Allan Kaprow, inventor del happening, forma heredera de las veladas del Black Mountain College, que incluye música, texto, danza, películas y producciones de objetos in situ. Kaprow también era seguidor de Pollock, del que dijo que "había destruido la pintura" en el sentido de que no pintaba, sino que se manifestaba "performaba"- a sí mismo a través del action painting, del mismo modo que Cage destruía la música. Pero en el primero había un claro condicionante: el lienzo, cosa que limitaba y que había que destruir. Y así fue como Kaprow se interesó por los objetos cotidianos, cuerpos y ropas como nuevos soportes.

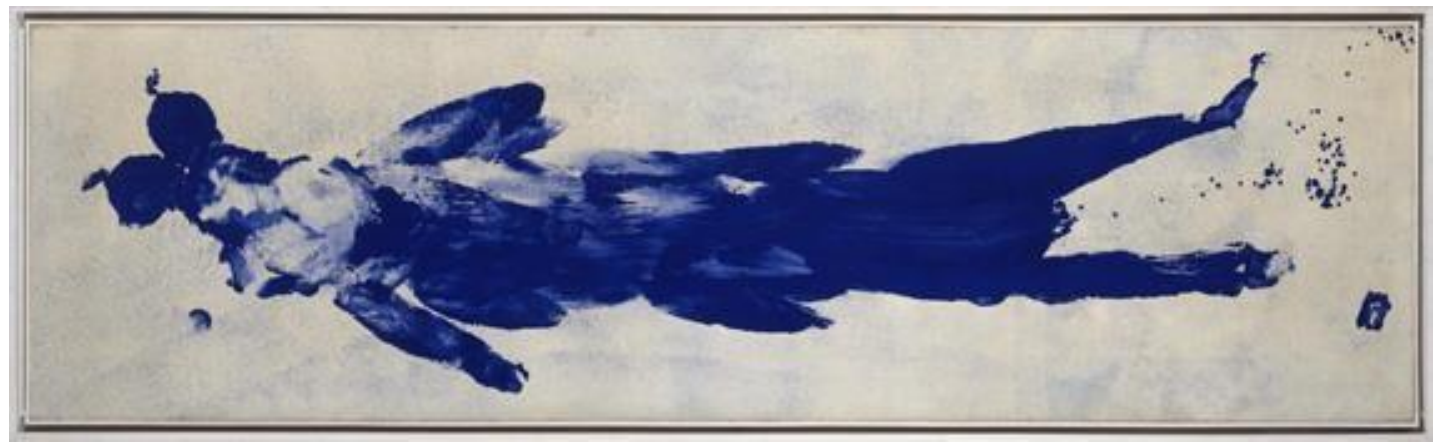

Fig. 2. Antropometría sin título (ANT 56), Ives Klein, 1960. Museo Reina Sofía.

${ }^{7}$ Entre otras cosas, Satie introducía hojas de papel entre las cuerdas de un piano en una búsqueda de un sonido mecánico. 
En 1959 Kaprow presenta en la Reuben Gallery de Nueva York 18 happenings in 6 parts, obra dividida en seis actos con tres happenings cada uno, que se desarrollaban en tres espacios independientes conectados por paneles translúcidos. El público fue quien ejecutó cada happening bajo un concepto lúdico y según unas indicaciones escritas en tarjetas -guion-, barajadas antes del inicio de las actuaciones para introducir el azar. Nadie sabía a lo que se enfrentaba. Entre otras cosas, los participantes tenían que subir una escalera, exprimir una naranja, sentarse en una silla, en definitiva: hacer cosas cotidianas sacadas del contexto habitual hasta oír una campanita que indicaba el final. Este fue el primer paso para la performance como tal: el público se convertía en la obra de arte y los objetos cotidianos herederos del ready-made- en el marco.

En el recorrido de antecedentes directos de fluxus queda una actuación que ejemplifica el poder que tuvieron -y tienen- las teorías de Duchamp y Cage. Yves Klein introdujo el bappening en Francia en 1960, dentro de la corriente Nouveau Realisme, con Antropometrías (figs. 2 y 3). Las antropometrías -medición del cuerpo humano- de Klein consistían en "mujerespincel": modelos desnudas empapadas en pintura azul que plasmaban su figura en grandes hojas de papel. La cosa no quedaba ahí, a veces invitaba a un público reducido y, mientras ellas "se pintaban", los espectadores bebían cócteles azules -del mismo azul que patentó- y un grupo de cuerda tocaba la pieza Monotone Silence Symphony, un único acorde compuesto por Klein repetido en el tiempo que duraba la acción.

La proliferación de happenings empezaba a solicitar mayor participación del público. El abandono de los soportes tradicionales, la ruptura con la modernidad, el rescate de Duchamp y los experimentos de Cage habían creado una nueva tipología: el arte conceptual empieza a ser reclamado y las tendencias son ya plenamente híbridas por la convivencia de movimientos artísticos o anti-arte y por la inclusión de nuevos medios. Estos avances darán lugar al fluxus y de él partirán el video arte o el mail art.

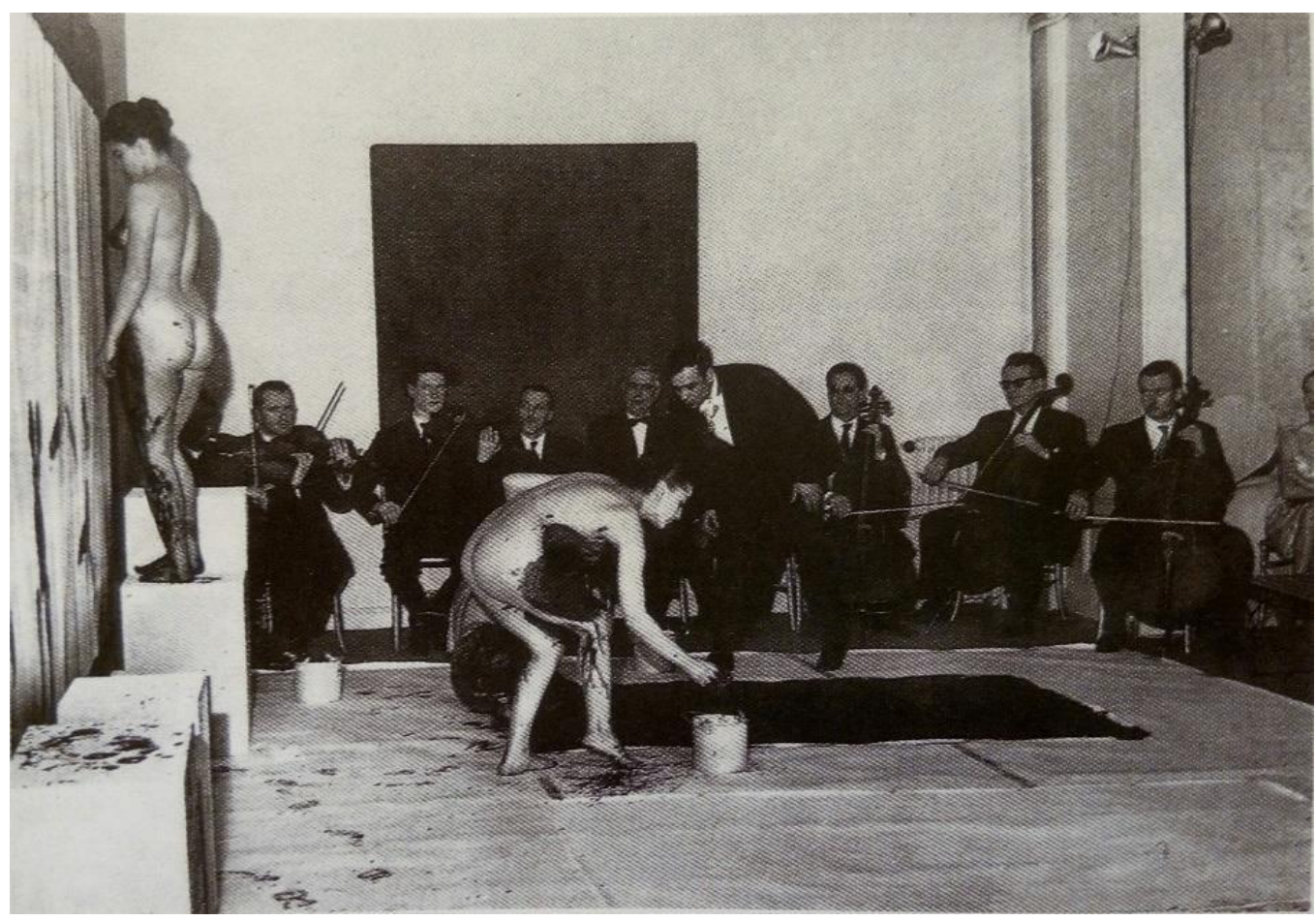

Fig. 3. Antropometrías. Fuente: VV.AA., Arte del siglo XX. Vol. II. p. 581. 


\section{Fluxus y zaj. Performances y performance sonora}

El piano es un tabú. Tiene que destruirse. Es más, no es cierto que sea tan caro... solo los costes del transporte son caros (Nam June Paik).

El fluxus fue un -no- movimiento artístico ${ }^{8}$ internacional surgido en la década de 1960 provocado por la hibridación del dadá, el productivismo y la aleatoriedad de Cage? . Fue paralelo al pop art y al minimalismo en Estados Unidos y al Nuevo Realismo en Europa. Fluxus se diferenciaba del neodadá en un mayor componente musical, mayor participación del público y la proliferación de actuaciones efímeras. Con fluxus, el bappening pasa a ser performance art ${ }^{10} \mathrm{y}$, en muchos casos, performance sonora.

"La performance escapa a una definición exacta o sencilla, más allá de la simple declaración de que es arte vivo hecho por artistas" (Goldberg, 1996, pág. 9), si bien, se producen unos leitmotiv en todas que facilitan la caracterización de las mismas: elemento temporal, espacial y corporal. La performance es un acontecimiento inmediato en la que el sujeto -cuerpo- es el soporte, manifestándose en un espacio y tiempo determinados y para un público partícipe de un discurso social y cultural (Kaiero Claver, 2007, pág. 336). Es una actuación efímera que no se puede conservar más allá de la fotografía o el vídeo. Se diferencia del teatro en que no hay hilo narrativo y el performer no es un actor, sino él mismo. El performer es un cuerpo biológico-cultural que manifiesta una idea específica que los espectadores interpretan en función de signos y significados. Cuando la performance tiene como tema principal la música, se convierte en performance sonora y se diferencia de un concierto en tanto que exhibe una experimentación musical y de manera improvisada, no piezas formadas anteriormente.

El fluxus apoyaba la práctica artística colectiva en un intento de negar la identidad y autoría. También promulgaba la mayor participación de las mujeres y por ello se le considera el primer movimiento artístico plenamente feminista. El fluxus era la combinación de arte y vida desde una perspectiva de acontecimiento y juego.

El nombre fluxus -del latín fluere, fluir- lo eligió George Maciunas, un artista emigrante lituano que se instaló en Nueva York en la década de 1950, donde conoció a John Cage y se interesó por la obra de Duchamp y los happenings de Kaprow (Gompertz, 2013, pág. 362). Maciunas asoció fluxus con catarsis corporal, descarga de excrementos y la transformación molecular y química. Pero, el término, con esas connotaciones, venía de lejos: se atribuye a Heráclito de Éfeso (s. V a. C.) la afirmación "todo está en continuo flujo, todo fluye"; y a Henri Bergson, a principios del XX, la consideración de que la evolución natural es un proceso de desarrollo y cambio continuo de "fluxión"

En 1962 Maciunas se traslada a Europa y realiza en Wiesbaden, entre el 1 y el 23 de septiembre, el primer festival fluxus, llamado Festival Internacional de la Nueva Música, donde se recuperaron algunas formas como el jazz. Allí actuaron cinco "violinistas" que jamás habían tocado un violín y que, además, debían componer música anti-violín en una declaración anti-música. Maciunas vuelve a Nueva York y, junto a Henry Flint crea Action Against Cultural Imperialism, donde fusiona el jazz con expresiones de arte popular (Guasch Ferrer \& Hernando Carrasco, 2000, pág. 80).

En 1963 Maciunas redacta el manifiesto fluxus, en lo que pretendía fuese una liberación "de la enferma cultura burguesa" y prometiendo la fusión "de los cuadros revolucionarios culturales, sociales y políticos en un frente de acción único", así como la promoción del "arte vivo". Maciunas -y con él, fluxus- quería purgar "al mundo del arte muerto, de la imitación,

\footnotetext{
${ }^{8}$ Los artistas fluxus definían el mismo como un movimiento no-artístico, desvinculándose de la historia del arte tradicional.

${ }^{9}$ El movimiento procede de la actividad de artistas exiliados, como "respuesta" al trauma de alejarse de la "patria" por conflictos bélicos. Entre los artistas fluxus había coreanos, alemanes, japoneses, etc.

${ }^{10}$ Forma híbrida al producirse a la vez distintos medios (cine, música, etc.). Como evolución del happening, la performance nace directamente del contexto posmoderno.

${ }^{11}$ Fluxión: del lat. fluxio -ōnis. 1. f. Acumulación patológica de líquidos en el organismo. DRAE.
} 
del arte artificial, del arte abstracto, del arte ilusionista, del arte matemático" (Román, 2016, pág. 42.) Fluxus rompía con todo.

Nam June Paik se adhiere a fluxus y realiza en 1962, en Colonia, One for Violin Solo (fig. 4), una performance en la que levanta lentamente un violín para después golpearlo contra una mesa hasta romperlo. Aún faltaban algunos años para que la práctica de romper instrumentos fuese habitual en las bandas y cantantes de rock.

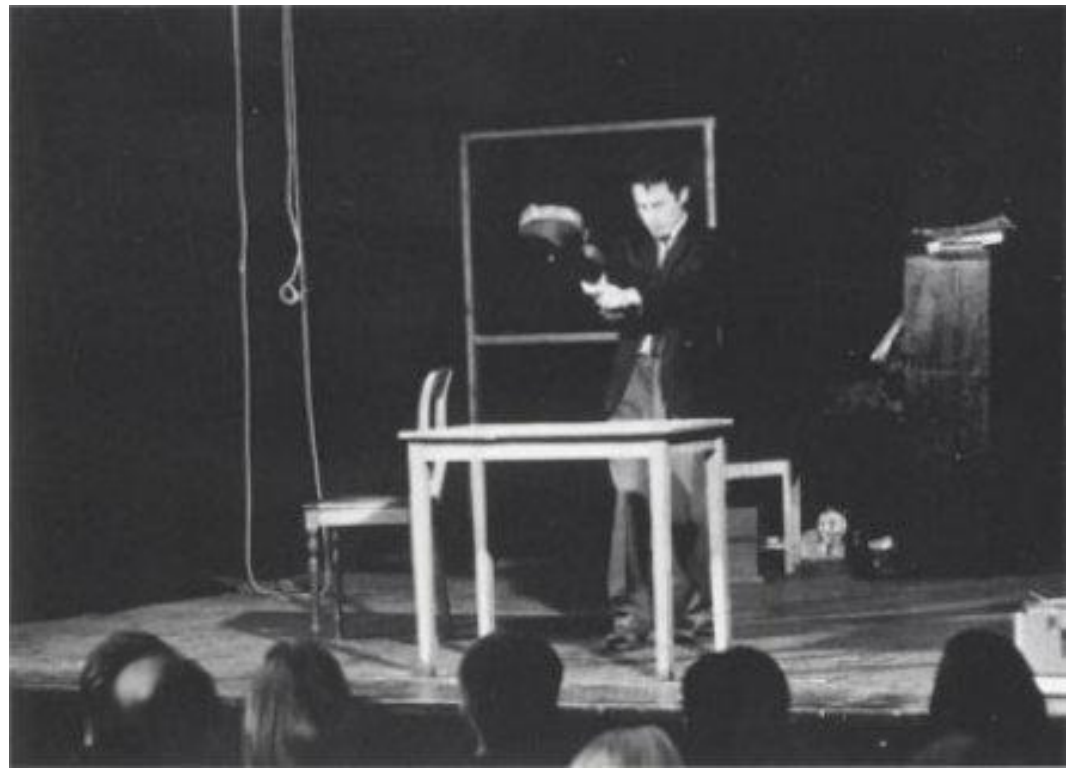

Fig. 4. One for Violin Solo, Nam June Paik, Colonia, 1962 (C) Nam June Paik, Foto: George Maciunas

Joseph Beuys firmó el manifiesto afirmando que la performance había dado paso a que el artista fuese el propio medio de su arte. Fue sonada Cómo explicar cuadros a una liebre muerta, realizada en 1965 en la galería Alfred Schmela de Düsseldorf, donde "explicaba" a una liebre muerta algunos cuadros allí expuestos. En base a esta actuación explicó tiempo después: "Se debió $[. .$.$] al hecho de que todo el mundo reconoce el problema que supone explicar las$ cosas, más concretamente cuando se trata de asuntos que forman parte del arte" (Gompertz, 2013, pág. 362). Sobre esta problemática también trabajó Yoko Ono, si bien, se centró en un zen-fluxus en el que la presencia de elementos sonoros y visuales era escasa, con la intención de buscar la meditación introspectiva del espectador.

Por su parte, en 1964 surge ZAJ en Madrid, siendo partícipes de la gestación los compositores Juan Hidalgo, Walter Marchetti -que conocieron a Cage y David Tudor en 1958 en Darmstadt- y Ramón Barce (Albarrán Diego, 2012, pág. 106). Un año después, el primer festival ZAJ acoge también a Tomás Marco y Ramiro Cortés y en 1968 se adhiere Esther Ferrer, con la que ZAJ cambiará hacia unos presupuestos más objetuales.

Con actividad hasta 1973, ZAJ se centró en conciertos de música concreta y acciones musicales con un fuerte componente visual. Había asumido los parámetros fluxus a partir de John Cage y de las teorías "duchampnianas". En relación a esto, Sarmiento define la práctica ZAJ así: "un concierto zaj, es ante todo, un espectáculo visual y una teatralización de la vida cotidiana donde están presentes el pensamiento zen y la familia zaj, es decir Duchamp (el abuelo), Cage (el padre), Satie (el amigo) y Durruti (el amigo de los amigos). Al que habría que sumarle Marinetti (el amigo olvidado)" (Sarmiento, Charles, Díaz Cuyás \& Barber, 1996, pág. 17). Así las cosas, ZAJ había traído el fluxus a España y, a partir de ellos, las performances proliferaron durante la década de 1970 bajo el deseo de libertad de acción en la dictadura y con una pobreza de medios ligados al arte povera.

A nivel global la performance se estaba coronando como la forma artística más representativa de la posmodernidad, comprendida por el público a medida que se iba 
expandiendo. La popularidad que ha alcanzado viene ejemplificada en la primera performance realizada en el MOMA a cargo de Marina Abramović en la primavera de 2010 y que formaba parte de una retrospectiva de la obra de la artista serbia titulada The artist is present. A lo largo de once semanas Marina Abramović estaba presente en el museo durante siete horas y media sin levantarse de una silla mientras en otra silla, colocada frente a ella, se sentaba un público que había esperado largas colas. En tal situación ocurría de todo: unos lloraban, otros decían que era la experiencia más espiritual de sus vidas, unos permanecían sentados durante más de tres horas frente a la artista y otros tan solo unos minutos. En fin, la perfomance fue la "obra" más visitada de la historia del MOMA.

\section{Morente y omega}

Acabo de pensarlo. Yo ya no quiero ser cantaor flamenco nunca más.

Desde hoy quiero ser cantante de rock $^{12}$.

Enrique Morente (1942-2010) comenzó su trayectoria a los 6 años cuando entra en el coro de canónigos de la Catedral de Granada. A los 18 se traslada a Madrid y comienza a cantar en los tablaos bajo el nombre de Enrique el Granaíno. Con el tiempo gana fama y en 1964 actúa en la Embajada y en el Pabellón de España en la Feria Mundial de Nueva York. Tres años más tarde comienza su carrera discográfica con Cante flamenco, cercano a la corriente purista pero con un sello particular y reportorio insólito.

En otro orden, a finales de los 60 la lucha contra la dictadura franquista llega al flamenco: los jóvenes artistas salen del círculo tradicional y toman contacto con la universidad y el círculo intelectual progresista. Entre ellos, Enrique Morente protagonizó una serie de recitales y coloquios en el Colegio Mayor San Juan Evangelista (Gutiérrez, 2006, pág. 45). En 1970, además de su labor en el San Juan, cantó poemas de Miguel Hernández en el Aula Magna de la Facultad de Medicina de Granada, hecho que se volvió eterno un año más tarde en su álbum Homenaje flamenco a Miguel Hernández. Siguiendo con esta labor, en 1975 vuelve a trasladar la poesía española al flamenco, esta vez homenajeando a Machado en Se bace camino al andar.

Sobre el cariz que estaba tomando el flamenco en el contexto universitario y el papel de Enrique Morente, el periodista Francisco Almazán señala en un reportaje de 1970, titulado "La escala del flamenco", dentro de la revista Triunfo:

"Enrique Morente [...] ha celebrado recitales en los colegios mayores de San Juan Evangelista y Alfonso X el Sabio, junto al veterano Juan Varea, Perico del Lunar y Humberto el Paíllo (un guitarrista holandés), como tocaores, y, por último, en el Isabel de España, acompañado por Antonio Piñana. Nos interesa destacar el carácter polémico de las intervenciones de Morente, promoviendo el coloquio y participando en él, como procedimiento didáctico de esclarecimiento, de los problemas que sobre el cante se plantean en la actualidad".

"Es ésta una experiencia (el recital dedicado a Miguel Hernández) a la hora de renovación del flamenco, que muchos podrían calificar como peligrosa o audaz, si los resultados conseguidos y la aprobación del público del Aula Magna, compuesta por viejos aficionados y universitarios, no hubieran demostrado que la cosa no era tan problemática y que, por el contrario, el contenido de esos poemas encaja perfectamente con el carácter popular del flamenco" (Gutiérrez, 2006, pág. 48).

La relación entre flamenco y Universidad mucho tuvo que ver en la creación del Nuevo Flamenco como subgénero, más allá de la naturaleza fusionista. En el contexto sociocultural nacional de finales de los 60, el flamenco neotradicional, por la "imposición" de Mairena, era entendido como establishment. En tal situación, los jóvenes flamencos, con Morente a la cabeza, entran en contacto con el círculo universitario y progresista a favor de una nueva vía flamenca y en contra de la censura franquista. En este sentido, el ya comentado Nuevo Flamenco se forma a partir de una subcultura -así lo define Steingress- que, si bien no está

\footnotetext{
12 Palabras de Enrique Morente recogidas por Jesús Arias (Galindo, 2011, pág. 58).
} 
en contra del establishment -en este caso funcionaría como contracultura ${ }^{13}$-, prefiere una alternativa con códigos distintos que un determinado público, afín a una ideología progresista, decodificaría, no identificándose con la corriente purista que entroncaría de mejor forma con los valores nacionalistas de la España franquista.

Pues bien, el flamenco nuevo de los primeros años de Morente iba más parejo a una reinterpretación experimental que a una manía de fusión. Desde finales de 1970 y durante la década de 1980, el cantaor granadino se dedicó a homenajear a los "grandes", como prueba el álbum de 1978 Homenaje a Don Antonio Chacón. No obstante, en 1990 la producción de Morente experimenta un cambio brutal bajo el eterno deseo de experimentación. Tras recibir en 1994 el Premio Nacional de Música, lanza en 1996 Omega, disco que lo consolida como cantaor innovador y con el que crea "otro" nuevo flamenco (Steingress, Morente y el flamenco como manifestación de la inquietud artística y social, pág. 271).

Omega es un trabajo conjunto de Morente y la banda de rock-noise granadina Lagartija Nick, con 13 composiciones de las que destaca la primera, homónima al disco, con una duración de 10' 48'. En él colaboraron numerosos artistas flamencos, incluso aparecen voces de grandes flamencos ya fallecidos mediante su inclusión en samplers.

Siguiendo la línea de musicalizar poemas, el trabajo cuenta con adaptaciones de Poeta en Nueva York de Lorca y de composiciones de Leonard Cohen. Al respecto, cierto germen de Omega se encuentra en la intención de desarrollar un trabajo profundo sobre el Lorca surrealista, cosa que llevaba tiempo persiguiendo el cantaor. Otro indicio corresponde a la propuesta que recibió Morente en 1991 de realizar un disco de versiones de Leonard Cohen y que, únicamente, supuso una toma de contacto con la obra del poeta y cantautor canadiense (Galindo, 2011, pág. 29).

Dos años más tarde Cohen y Morente se conocen en Madrid y el cantaor retoma el proyecto sobre el canadiense. Llegados a este punto irrumpen los coprotagonistas Lagartija Nick que se incorporaron al proyecto por mediación de Jesús Arias, bajista de la banda granadina y hermano del vocalista, el cual llevaba tiempo obsesionado con la idea de grabar poemas de Lorca mezclando punk y flamenco. Por su parte, Raúl Alcover, que ya colaboraba con Morente, fue el verdadero nexo entre el cantaor y los hermanos Arias.

En 1995 se produjo el encuentro entre Morente y la banda de rock, quedando cerrado el proyecto, si bien con un cambio de rumbo: Enrique había abandonado su intención de crear un disco próximo al pop, prefiriendo un sonido más inconformista a la vez que un menor protagonismo de Cohen y una mayor dedicación a Poeta en Nueva York.

Los ensayos se prolongaron durante buena parte de 1996 y, excediendo todas las previsiones, de un único tema, "Omega", de 3 minutos, se llegó a una versión final de casi 11 y al disco que conocemos. La dimensión y forma que alcanza esta primera composición hace que pueda ser entendida como una suite por componerse de varios fragmentos que se integran en torno a un compás variado (Steingress, Morente y el flamenco como manifestación de la inquietud artística y social, pág. 272); o bien, como una pieza de rock progresivo que se fusiona libremente con el flamenco (Galindo, 2011, pág. 53). En cuanto al uso de la guitarra flamenca, en el disco es tratada como si fuese una guitarra eléctrica con tintes melódicos (Barrera Ramírez, 2014, pág. 76).

Considerado como el mejor trabajo discográfico español de 1996, Omega se convirtió en el primer disco de flamenco fusionado con rock que logró pronto la aceptación del público y crítica, dando a lugar también a la asimilación de La Leyenda del Tiempo de Camarón diecisiete años después (Barrera Ramírez, págs. 47 y 48).

Antes de Omega Morente ya había "flirteado" con el rock: en 1975 colaboró con el trabajo de Gualberto $A$ la vida, al dolor. En ese mismo año quedaron grabados los primeros frutos de sus trabajos de experimentación, como la seguiriya "Misa flamenca", recogida en Se hace camino al andar. Más allá de Morente, Omega supone un paso más de lo que había iniciado

${ }^{13}$ La contracultura es heredera del movimiento hippie, se caracteriza por una ideología propia y se mueve en instituciones propias alternativas. La subcultura, por el contrario, es una forma simbólica de resistencia, con una oposición menos articulada (Rodríguez González, 2002, pág. 32). 
Sabicas con Joe Beck en Rock Encounter (1970) y continuado, a la manera de cada uno, por artistas del Nuevo Flamenco como Lole y Manuel, Las Grecas o Triana.

Omega también abrió una vía de experimentación para otras bandas indies como Sr. Chinarro o La Bien Querida y, más tarde, para el grupo tributo a Morente Los Evangelistas, formado por Antonio Arias y J, Eric y Florent de Los Planetas, que en 2012 publicaron Homenaje a Enrique Morente (El Ejército Rojo, 2012), un álbum en el que revisan doce composiciones de Enrique Morente y en el que colaboran, entre otros, Soleá Morente y Carmen Linares. En este punto cabe citar que Morente colaboró con numerosos grupos, sobre todo granadinos, como fue el caso de Los Planetas. El álbum La Leyenda del Espacio de Los Planetas (2007, RCA Records), nació bajo la influencia de Enrique Morente, con melodías inspiradas en el flamenco y con la interpretación del propio Morente en "Tendrá que haber un camino", donde se le da mayor importancia a la vOz que a la instrumentación (Barrera Ramírez, pág. 84).

\section{Escena underground y rock experimental. Sonic youth como colectivo de artistas}

I'll be your mirror, reflect what you are

(The Velvet Underground, 1967)

El movimiento underground ${ }^{14}$ nace en la década de 1960 de la mano de universitarios estadounidenses contrarios al establishment con el deseo de formar una cultura al margen de la oficial. En cuanto a la producción artística, está relacionado con la creación de exposiciones en galerías independientes, revistas, y tertulias centradas en una filosofía propia al margen de la sociedad de consumo y entendida como contracultura.

En la misma línea fluxus, los artistas que se establecieron en el Nueva York underground cuestionaron el arte como sucesión de estilos y dependiente de instituciones oficiales ${ }^{15}$. En este contexto, el Do It Yourself (DIY) se convirtió en el modelo preferido de producción y distribución cultural, alcanzando su cumbre en el punk. El DIY es entendido como la autoproducción -contracultural- al margen de las instituciones oficiales, permitiendo que cualquier artista pudiese sacar a la luz su trabajo (Gallego Pérez, 2009).

El underground americano se manifestaba a través de variantes del rock, la droga y los cómics, y se irradió en Europa bajo los mismos parámetros. En lo que atañe al rock como identificación de este movimiento, se produce según la contribución de la música experimental de Cage $^{16}$ y bajo el deseo de romper con los principios institucionales musicales oficiales.

La música experimental, nacida en Norteamérica, representa per se la posmodernidad al abandonar la estética moderna bajo una intención de de-construir algunos hechos definitorios de la modernidad como la autoría o la autonomía de la música, proponiendo opciones que rebaten dicha autonomía a partir de fluxus, como performances y arte sonoro, calificativos nuevos diferentes al de "música".

Antecedentes de la música experimental fueron los futuristas con sus experimentos acerca del ruido ${ }^{17}$-el noise surgirá a finales de 1970 como subgénero del rock a partir de la

\footnotetext{
${ }^{14}$ Mario Maffi denominó cultura underground a un producto híbrido, resultado de ciertas condiciones sociales, políticas y culturales determinadas, con origen en la generación beat (García, 2008, págs. 189-190). La generación beat es revisada por Dick Hebdige: surgida a mediados de la década de 1940, de una identidad compartida con los negros (simbolizados en el jazz) -al igual que los hípsters-, los beats eran estudiantes de clase media que reflexionaban sobre la pobreza como esencia divina. El movimiento beat fue decisivo en la formación de la contracultura hippie, al compartir el deseo de liberación sexual y buscar los derechos de negros y mujeres (Hebdige, 2004). 2002).

${ }^{15}$ Para abordar de manera más profunda el contexto artístico de la escena underground neoyorquina: (Taylor,

${ }^{16}$ Cage define música experimental como aquella que investiga, sin conocerse los resultados sonoros a priori (Cage, 1976, pág. 42).

${ }_{17}$ En 1910 Francesco Balilla Pratella escribe el Manifiesto de los músicos futuristas. Tres años más tarde Luigi Russolo publica El arte de los ruidos, con el propósito de incluir la velocidad, la electricidad y el ruido de las fábricas en la música (Ruesga Bono, 2004, pág. 40).
} 
contribución de los músicos futuristas y caracterizado por la introducción de elementos ruidistas-, así como los compositores Satie y Varèse ${ }^{18}$ y la atonalidad como renuncia de cualquier organización, contraponiéndose a la vanguardia serial europea (Kaiero Claver, 2007, pág. 221). Supone una corriente alternativa, al margen de la evolución oficial de la historia de la música, desarrollada fuera de los circuitos oficiales.

Ya dentro del rock experimental -o vanguardista- destacó The Velvet Underground, capitaneada por Lou Reed y John Cale y producida por Andy Warhol. En activo desde 1964 hasta 1973, la banda neoyorquina representaba la escena underground en el campo musical: letras nihilistas que hablaban de travestismo y drogas, y música ruidosa llena de distorsión. The Velvet Underground fue el espejo en el que se reflejaron muchos grupos noise de los 80 y 90, por citar algunos: los estadounidenses Pixies y Sonic Youth y los granadinos Los Planetas (Bianciotto, 2008, pág. 267).

Así las cosas, vanguardias artísticas, rock experimental, DIY y contracultura son conceptos relacionados con el movimiento underground, desarrollado al margen de instituciones oficiales y contrario al establishment, surgido en Norteamérica y exportado a Europa.

Sonic Youth se ajusta a tales principios. La banda surge en Nueva York en 1981 y es catalogada, entre otros subgéneros, como noise rock y rock experimental. En su inicio estaba formada por el guitarrista y vocalista Thurston Moore, el bajo Kim Gordon, Richard Edson en la batería, reemplazado por Bob Bert y más tarde por Steve Shelley, y Anne DeMarinis en los teclados. Gordon se había formado como artista plástico y ejercía de comisario en algunas galerías neoyorquinas al mismo tiempo que publicaba ensayos sobre arte en la revista Artforum (Groenenboom, 2010).

En el mismo año de formación Sonic Youth participó en el Noise Fest, un festival de música experimental organizado por Thurston Moore en la sala White Columns de Nueva York, que se celebró durante nueve días. Para el festival Kim Gordon organizó una exposición de obras plásticas creadas por artistas visuales que también tocaban en grupos underground. Tras el Noise Fest, DeMarinis abandona la formación y el artista visual Lee Ranaldo, componente de la banda The Fluks, entra como guitarrista en Sonic Youth. Por aquel entonces artes plásticas y música se desarrollaban como una única forma híbrida -como "prolongación" de fluxus- hecho que abordó la banda neoyorquina durante toda su trayectoria en tanto que fusionó arte conceptual, música experimental y la rebeldía del punk.

\section{Morente y sonic youth en el ca2m}

¡Siempre estás con las modernuras! ${ }^{19}$

En mayo de 2005 Morente y Sonic Youth actúan en el Primavera Sound, cosa significativa en cuanto a que un artista flamenco -aunque a partir de Omega, roquero- formaba parte de un cartel de música underground. Cuando Morente escuchó en directo a Sonic Youth se propuso colaborar con ellos (Galindo, 2011, págs. 156-157). En octubre de ese mismo año la colaboración se hace realidad en el Heinenken Greenspace de Valencia, un certamen de música, cine y diseño para el que habían ensayado tan solo el día anterior en París, para el que se desplazó Morente. La colaboración tomó forma en la reedición de Omega (2008), en la canción "Oriente y Occidente".

En 2010 Morente se vuelve a reunir en Móstoles con Lee Ranaldo y Steve Shelley, con motivo de la exposición itinerante retrospectiva SONIC YOUTH, etc.: SENSATIONAL $F I X^{20}$, comisariada por el holandés Roland Groenenboom y celebrada en el Centro de Arte 2 de mayo, durante el 3 de febrero y el 2 de mayo.

18 Vàrese aplica sonidos electrónicos en sus composiciones con la intención de no diferenciar entre sonido musical y ruido.

19 Aurora Carbonell a su marido Enrique Morente (Viana, 2010).

20 Parte de la exposición y de la performance que aquí analizamos se encuentra alojada en: https://www.youtube.com/watch?v=aRQSqZDrBUo 
La exposición, que contaba con obras de artistas ligados a la escena experimental, fluxus y underground-Maciunas y Cage entre otros.- se centraba, además de en la trayectoria de Sonic Youth, en la reflexión de temas propios de la cultura contemporánea: debate religioso, cuestiones de género, moda y fama, manifestados a través de fotografías, fanzines, portadas de discos y otros medios que traducían de manera gráfica el cambio sociocultural de finales del siglo XX, en lo que se pretendía como exhibición asentada en la cultura visual y el ruido.

Parte importante de la exposición fueron los audiovisuales, dedicados en su mayoría a una reflexión sobre música, en la órbita Cage-fluxus y en la propia idiosincrasia de Sonic Youth. Se proyectaban, entre otras cosas, un piano percutido mediante un martillo que ponemos en relación con el piano preparado de Cage, los conciertos ZAJ y la práctica fluxus de cambiar la función del objeto y la manera de ejecutarlo; una guitarra eléctrica es "tocada" como un violín, deslizando el arco por el mástil; y la representación temporal del sonido amplitud/tiempo- emparejando a través de la imagen los conceptos tiempo y espacio/ imagen y sonido, también en la línea de fluxus y performances sonoras. En fin, las proyecciones ponían al espectador en relación con el contexto cultural contemporáneo -tecnología, nuevos medios y música experimental- y estaban desprovistas de textos explicativos, con el propósito de que el público las interpretase en función de su capital cultural ${ }^{21}$.

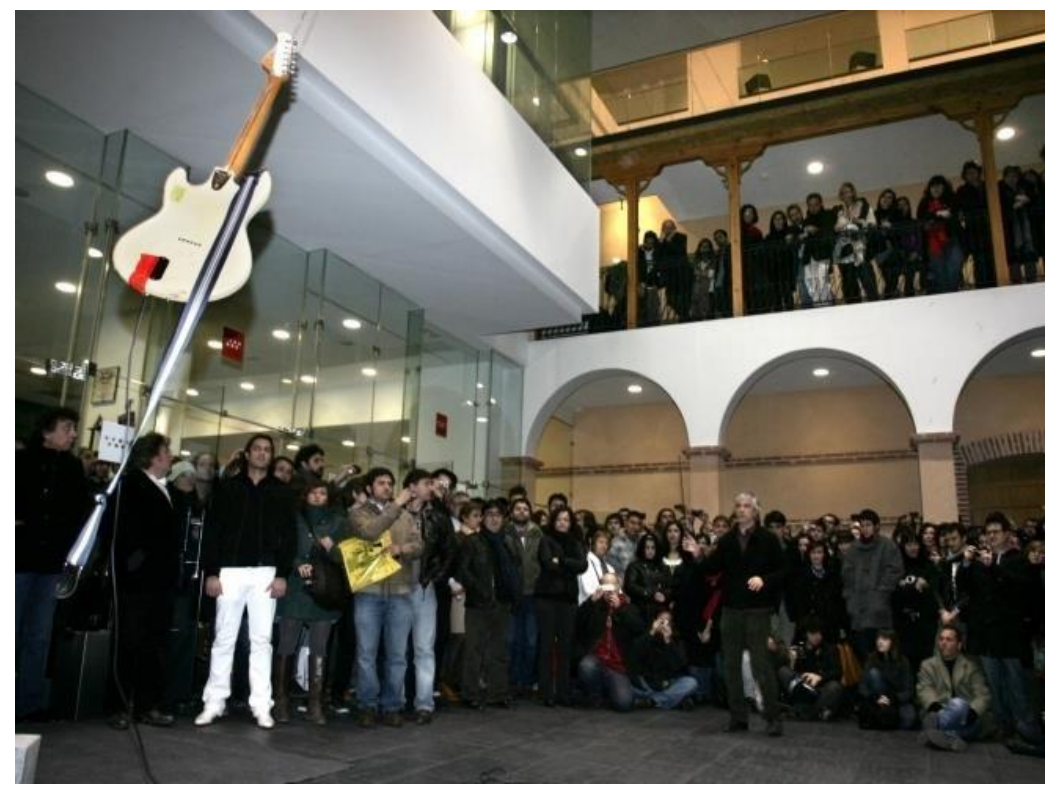

Fig 5. Lee Ranaldo espera a que la guitarra eléctrica llegue a él para volverla a lanzar. Fuente: CA2M.

El 2 de febrero quedaba inaugurada dicha exposición con una performance sonora realizada por Ranaldo, Shelley y Morente, que venía acompañado de Isaac de los Reyes y Pedro y Ángel Gabarre. A las 20:30 decenas de jóvenes ligados al rock alternativo (Llano, 2010) se agolparon en el vestíbulo del CA2M alrededor de una guitarra eléctrica que pendía del techo por un cable de acero. En el centro del espacio estipulado para la actuación se encontraba Lee Ranaldo y, frente a él, Morente y sus acompañantes junto a Shelley a la batería.

Cada protagonista tenía una función en la performance entendiéndose esta como hecho colectivo: Morente canta un martinete, elección interesante por ser canto primitivo y en la órbita del purismo y que a la vez se transforma hacia la corriente innovadora por la intención de fusión; por otra parte, al tener un ritmo libre y ser más propenso a la improvisación, el

${ }^{21}$ Según la teoría del sociólogo Pierre Bourdieu, y de manera muy simplificada, el capital cultural atiende al propio bagaje, al conocimiento adquirido mediante instituciones educativas o no. El capital cultural funciona para Bourdieu como prejuicio a fin de ser una herramienta interpretativa. 
martinete es más fácil de "manejar", de adaptarlo a otro contexto musical; Isaac de los Reyes baila, Pedro y Ángel acompañan con palmas; Shelley toca la batería; y Lee Ranaldo entrechoca dos baquetas y golpea la guitarra que pende con las mismas, haciéndola mover como un péndulo además de frotar con un arco de violín el mástil (figs. 5 y 6).

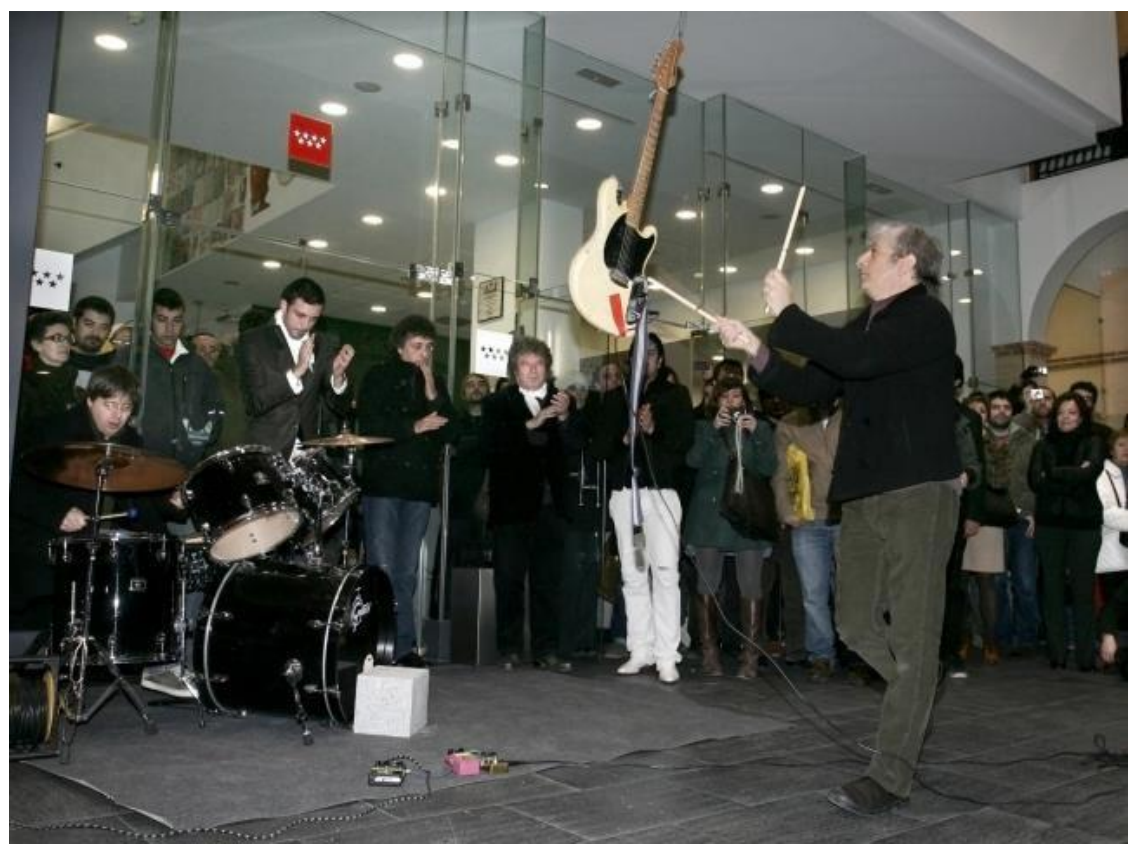

Fig. 6. Lee Ranaldo golpea el encordado de la guitarra con unas baquetas. Fuente: CA2M.

En la performance se diferencian dos elementos sonoros. Por un lado, el flamenco y por otro el rock. El primero viene representado por el martinete, las palmas y el baile. En relación al martinete, es el único elemento vocal y no presenta texto musical, atendiendo solo al puro timbre vocal de Morente. Dichos elementos mantienen su función: Morente y "familia" actúan de manera ortodoxa, como un grupo de flamenco. En este sentido no conviene tratar a los palmeros, bailaor y cantaor como performers, ya que no quedan desprovistos de su función.

Por su parte, el rock aparece bajo un concepto experimental pero representado por elementos descontextualizados y deconstruidos. La batería es el único elemento que no pierde su función, mientras que la guitarra se descontextualiza al no ser tocada de manera habitual: golpeada por Ranaldo funciona tan solo como medio para producir distorsión, en una búsqueda de posibilidades sonoras alternativas. Al respecto, el rock solo es reconocible por los elementos que lo caracterizan de manera visual, pues la sonoridad que producen no se ajusta a la naturaleza del género musical.

Las dos masas sonoras mantienen un constante diálogo, si bien no hibridizadas por diferenciarse ambas partes y reproducirse el flamenco bajo sus signos naturales. De esta menara, lo que aquí acontece es una fusión de géneros, en tanto combinación integral de ambas masas. Así, podríamos rescatar el título de la canción conjunta de Sonic Youth y Morente en la reedición de Omega, porque "Oriente" es flamenco y se produce "como flamenco" y "Occidente" es la parte artificial, la que experimenta bajo la descontextualización y deconstrucción.

El tratamiento de la guitarra eléctrica merece un comentario exclusivo. La guitarra es el objeto central de la performance: los ejecutantes y el público se colocan en torno a ella. El hecho de que Ranaldo la manipule, la aleja de ser únicamente un elemento expuesto en el contexto museográfico. Al estar colgada del techo mediante un cable de acero, permite la manipulación 
alternativa del performer en lo que se manifiesta como condicionante doble: la guitarra sigue un movimiento en función del empuje de Ranaldo y este se mueve en el espacio en función del movimiento de la guitarra, lo cual entroncaría con la aleatoriedad de Cage. Por otra parte, al golpear el encordado de la guitarra con baquetas y frotar el mástil con un arco de violín, se produce una distorsión que envuelve la sala en un sonido ambiental a partir de amplificadores. Tal sonido, por la intención experimental y el "ruido" entra en relación con las corrientes fluxus, ZAJ, el noise y la música futurista.

Tras zarandearla, Ranaldo se sube a una papelera metálica para descolgar la guitarra. Una vez en sus manos lanza la papelera, rompiéndola, y comienza a golpear el mástil contra el suelo, primero de la guitarra descolgada y luego de una segunda. La práctica de golpear y romper instrumentos ha sido citada a lo largo de este trabajo -recordemos One for violin solo de Nam June Paik- pero, más allá del campo musical, cabe destacar y relacionar este hecho con otras acciones en el campo del arte. Por citar alguna de estas acciones, es famosa Tirando al suelo una urna de la dinastía Han (1995) del artista chino Ai Weiwei. Como el propio título advierte, Ai Weiwei dejó caer un jarrón de la dinastía Han (202 a. C - 220 d. C), acción que quedó plasmada en la serie de tres fotografías en blanco y negro (fig. 7 y que tenía como objeto cuestionar el culto a determinados objetos, la construcción historiográfica como verdad absoluta basándose en el principio falsedad -se ha venido diciendo que la urna era una falsificación-, y el poder del mercado de arte.

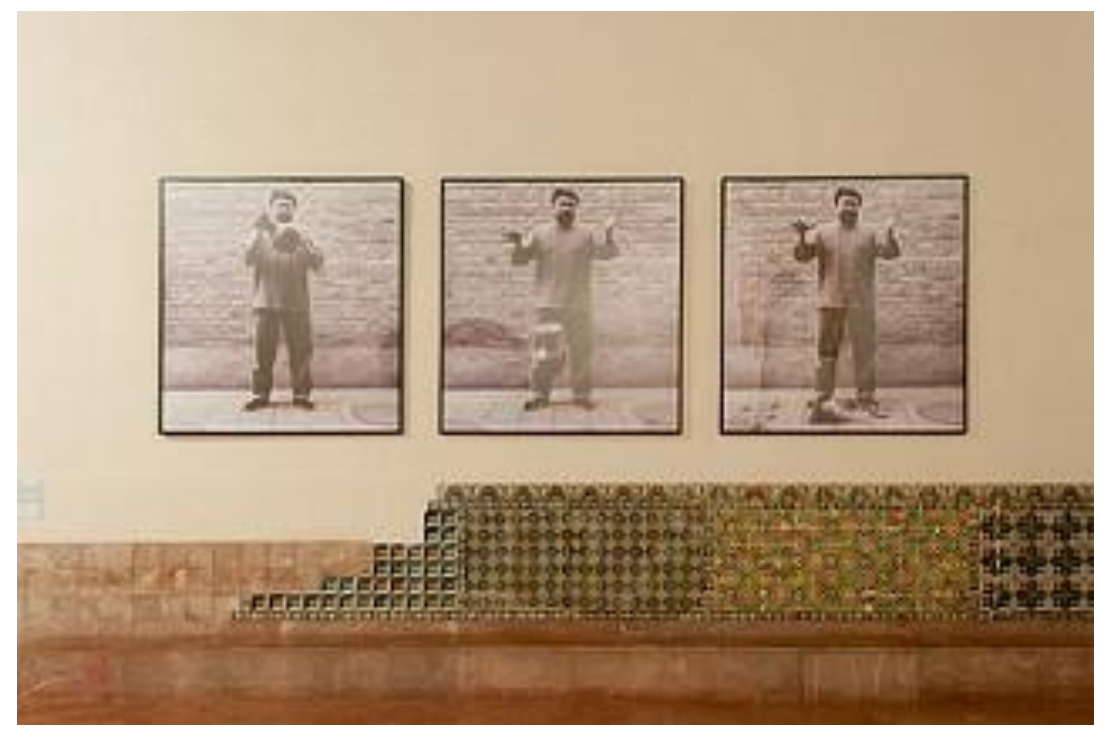

Fig. 7. Tirando al suelo una urna de la dinastía Han. Ai Weiwei, 1995. Fuente: CAAC, Sevilla.

Comparemos ahora la performance de Morente y Sonic Youth con las mencionadas: Nan June Paik golpea un instrumento ligado a la música culta, en un contexto en el que la música popular se difundía masivamente a través de los medios de comunicación; Weiwei niega la antigüedad como valor y juega con la dualidad verdad/falso; Ranaldo no llega a romper la guitarra pero la golpea del mismo modo que Paik el violín, en lo que podríamos entender, además de como acto punk y medio de distorsión, como la ruptura con el culto de los instrumentos musicales ligados al rock, en tanto que la práctica "ortodoxa" de romper guitarras por los grupos de rock ha sobrepasado los escenarios para hacerlo fuera del contexto habitual, en el museo. $\mathrm{O}$, una segunda interpretación: tras el carácter popular que ha adquirido por los mass media el rock, en su corte experimental, vuelve a un origen underground en tanto que la idea de "rock" se exhibe en un centro de arte contemporáneo y en cuanto a que prevalece el concepto y no la función del género, en simbiosis con las artes visuales y el rescate de fórmulas duchampnianas. 
Ahora volvamos al flamenco, ¿qué sentido tiene la performance si los agentes que la conforman no pierden su función habitual? En primera instancia, no es el flamenco "general" lo que aquí compete, sino el flamenco de Morente, sobre todo, a partir de Omega. La intención de Morente se podría entender como una prolongación de la reedición de Omega, si bien no eligió esta vez una obra ya hecha ni hizo una pieza nueva, sino la pura improvisación, la adaptación del flamenco al ruido experimental y no como accesorio, más bien como nueva posibilidad en el campo del flamenco, que estaba a punto de entrar en la Lista del Patrimonio de la Humanidad y que, una vez dentro, sorprende la definición estipulada por la UNESCO:

"El flamenco se interpreta con motivo de la celebración de festividades religiosas, rituales, ceremonias sacramentales y fiestas privadas. Es un signo de identidad de numerosos grupos y comunidades, sobre todo de la comunidad étnica gitana que ha desempeñado un papel esencial en su evolución. La transmisión del flamenco se efectúa en el seno de dinastías de artistas, familias, peñas de flamenco y agrupaciones sociales" (UNESCO, 2010).

Pues bien, el flamenco de Morente fusionado con el rock experimental de Sonic Youth no se ajusta a tal definición y, sin embargo, suena a flamenco porque presenta signos sonoros y visuales de "flamenco". Por su parte, Morente seguía consiguiendo alejar "flamenco" de la vertiente romántica, logrando cuestionar en cada trabajo los conceptos de "puro" y "tradicional". La parte flamenca de la performance no se ajusta a un propósito ritual, ni religioso, ni privado, sino más bien se asienta en la globalización, en la correspondiente transculturación y, de manera específica, en la experimentación, ajustándose al objeto de la performance sonora: en el carácter global del flamenco y en la capacidad de adaptarse a otros géneros musicales y de adaptar otros géneros musicales al flamenco.

Una vez hecha la interpretación hermenéutica, conviene analizar el público y la trayectoria de los que realizan la performance desde una perspectiva sociológica. Sobre los espectadores, debían conocer y escuchar a la banda neoyorquina, porque la performance era el reclamo para iniciar una exposición centrada en su trayectoria. Al respecto, el gusto de los espectadores entroncaría con la escena underground y las nuevas formas artísticas, esto es: debían conocer una performance en función de su capital cultural y este a su vez condicionaría su consumo cultural. En función de esto, se podría definir que los que visitaron el CA2M el 2 de febrero de 2010, formarían parte de grupos habituados al consumo de rock experimental/ noise, en la órbita de las bandas surgidas a partir de The Velvet Underground. Además, el público debía conocer el flamenco, no en su vertiente purista sino en el contexto de fusiones e hibridaciones, en un proceso de entender el flamenco de igual manera que el rock: como fenómeno global fusionado con otras músicas.

Siguiendo en esta línea, se hace interesante revisar de manera sintetizada la trayectoria de Sonic Youth y Morente. Ambos formaron parte de un contexto cultural "alternativo" en relación a círculos universitarios y progresistas, por lo que en tal situación cambiaron su percepción, manifestándose en un campo determinado: Morente -aunque también con trabajos dentro de la vertiente purista- había llegado a una subcultura flamenca, a una alternativa al establishment mairenista; Sonic Youth, por su naturaleza de músicos y artistas plásticos, se desenvolvía dentro de la escena underground, en un contexto artístico híbrido que partía de fluxus y Cage. Tanto el cantaor como los de Nueva York conocían los procesos de cambio en sus campos y cambiaron sus capitales culturales en función de su recorrido: cuanto más conocían, más "enriquecían" sus trabajos en una constante "lucha" de posición en el campo de flamenco/ rock experimental.

\section{Conclusiones}

A lo largo de este trabajo hemos pretendido cuestionar el Nuevo Flamenco como corriente en la que se asientan los trabajos experimentales de Enrique Morente. Si bien es cierto que, por su carácter transgresor y fusionista, la labor del cantaor ha entrado en relación con dicha corriente, consideramos que sobrepasa al Nuevo Flamenco para establecerse como algo plenamente novedoso, en consonancia con los cambios que se producen en el campo artístico a partir de la segunda mitad del siglo XX. Morente hizo "otra cosa" a partir del Nuevo Flamenco, dentro de los presupuestos posmodernos de hibridación y, como Sonic 
Youth, practicó la fusión musical y artística e hizo uso de escenarios no propios del flamenco (festivales de música alternativa y centros de arte). Así las cosas, se podría decir que la figura de Enrique Morente funciona como paradigma en el campo flamenco, pues abre una nueva etapa en el flamenco más allá de lo "nuevo".

De manera general, en este trabajo se ha destacado la capacidad de adaptación del flamenco al cambio sociocultural, de modo similar a otras artes y movimientos comentados. Incluso la corriente purista, supuestamente hermética, no se desarrolló de la misma manera en las distintas etapas historiográficas del flamenco.

Ya centrándonos en las vanguardias artísticas, hemos comprobado que fueron tan determinantes para la creación de nuevas formas en la música y las artes plásticas, como los mass media. En lo que a nuestro trabajo respecta, el antecedente más claro fue fluxus, heredero del conceptualismo, de importantes consecuencias en el campo musical. Fluxus, que se ajusta al contexto posmoderno en el que primaba la individualidad frente al sentimiento colectivo de nación, niega la autoría y aboga por colectivos de artistas entendidos como "pequeñas sociedades" (emisores) cuyos individuos trabajan colectivamente para otras "pequeñas sociedades" (receptores), cuyo similar bagaje cultural garantiza la comprensión de la obra y su creación colectiva.

De manera más específica, la música underground, así como algunas obras experimentales de la producción culta contemporánea, son deudoras de los trabajos de John Cage, artista revolucionario que propuso nuevas formas de expresión musical que luego fluxus y ZAJ, entre otros, tomarían en su producción. El desarrollo de la escena underground en este trabajo permite poner en relación flamenco, circuitos independientes y público afín a dicha escena alternativa.

Por su parte, la performance se corona como forma artística plenamente posmoderna en tanto que surge de la hibridación de varias artes y se desarrolla bajo presupuestos experimentales y reivindicativos dentro del contexto cultural, artístico y político. La aquí analizada es una performance sonora para cuya completa comprensión ha sido precisa la referencia a los principales hitos en el campo del arte y la cultura visual desde mediados del siglo XX.

En cuanto a la participación de Enrique Morente en la performance tratada, es deudora de los constantes trabajos de experimentación en el flamenco y de lo que comenzó con Omega, logrando la hibridación y la interrelación entre artes, así como la aceptación del público, ya no sólo de sus trabajos discográficos, sino de su participación en escenarios de música indie $\mathrm{y}$ en centros de arte. 


\section{Bibliografía}

091. (1989) ¿Qué fue del siglo XX? Doce canciones sin piedad.

Albarrán Diego, J. (2012). Del fotoconceptualismo al fototablèau. Fotografía, performance y escenificación en España (1970-2000). Salamanca: Universidad de Salamanca.

Barrera Ramírez, F. Un rockero llamado Enrique Morente. En torno a Omega (1996). Granada: Universidad de Granada. (2014).

Bianciotto, J. Guia universal del rock: de 1990 basta hoy. Barcelona: Ma Non Troppo. (2008)

Cage, J.. Pour les oiseaux. Entretiens avec Daniel Charles. París: Belfond. (1976).

Foster, H. Arte desde 1900: Modernidad, Antimodernidad, Posmodernidad. Madrid: Akal. (2006).

Galindo, B. Omega. Historia Oral del album que unió a Enrique Morente, Lagartija Nick, Leonard Cohen y Federico García Lorca. Madrid: Lengua de Trapo. (2011).

Gallego Pérez, J. Do It Yourself. Cultura y tecnología. ICONO (13), (2009)., 278-291.

Gamboa, J. M. Una historia del flamenco. Barcelona: Espasa. (2011).

García, D. El lugar de la autenticidad y de lo underground en el rock. Nómadas (29), (2008). 187-199.

Goldberg, R. Performance art. Barcelona: Ediciones Destino. (1996).

Gómez, I. S.. John Cage y su influencia en la obra del video artis ta Nam June Paik. Anuario Música (64), (2009), 239.

Gompertz, W.. ¿Qué estás mirando? 150 años de arte modern en un abrir y cerrar de ojos. Madrid: Taurus. (2013).

González Alcantud, J., \& Lorente Rivas, M.. Transculturaciones flamencas. Varia inflexiva. TRANS, no 8. (2004).

Groenenboom, R. SONIC YOUTH, etc.: SENS ATIONAL FIX. (2010)

Guasch Ferrer, A. \& Hernando Carrasco, J. . Arte del siglo XX. De la Segunda Guerra Mundial hasta nuestros dias. (Vol. 11). Madrid: Espasa. (2000)

Gutiérrez, B. . Enrique Morente. La voz libre. Madrid: Iberautor. (2006)

Hebdige, D. . Subcultura. El significado del estilo. Barcelona: Paidós. 2004)

Jameson, F. (Teoría de la posmodernidad. Madrid: Trotta. (1996).

Jiménez, J. Arte es todo lo que los hombres llaman arte. En J. Jiménez, Teoría del arte (págs. 17-52). Madrid: Alianza Editorial. (2004).

Julián, I. Arte del siglo XX. De principios de siglo a la Segunda Guerra Mundial (Vol. 10) Madrid: Espasa. (2000).

Kaiero Clavel, A. Creación musical e ideologías: la estética de la postmodernidad frente a la estética de la modernidad. Barcelona: Universidad de Barcelona. (2007).

Llano, P. D. (3 de febrero de 2010). Morente se fusiona con Sonic Youth. El País.

Martí, J. . Transculturación, globalización y músicas de hoy. TRANS nº 8. (2004)

Peinazo, D. G. Rock andaluz, orientalismos e identidad en la Andalucía de la transición (1975-1982). En J. Marín López, G. Gan Quesada, E. Torres Clemente \& P. Ramos López (Ed.), Musicología global. Musicología local (págs. 759-778). Madrid: Sociedad Española de Musicología. 2013).

Peinazo, D. G. . Prácticas culturales en torno al rock andaluz. Entre el imaginario y la nostalgia de Andalucía. En F. García Gallardo \& H. Arredondo Pérez (Ed.), Andalucía en la música. Expresión de comunidad, construcción de identidad (2014) (págs. 151-171). Sevilla: Centro de Estudios Andaluces. Junta de Andalucía.

Rocca, A. V. . Arte conceptual y postconceptual. La idea como arte: Duchamp, Beuys, Cage y Fluxus (U. C. Madrid, Ed.). Nómadas: revista crítica de ciencias sociales y jurídicas 37 (1), (2013), 248.

Rodríguez González, F. . El lenguaje de los jóvenes. Barcelona: Ariel. (2002)

Rogers, R. From Cultural Exchange to Transculturation: A Review and Reconceptualization of Cultural Appropiation. Communication Theory, $\mathrm{n}^{\circ}$ 16. (2006).

Román, A. Indeterminación y Minimalismo, Pop y Vanguardias. Estetización de la música de la segunda mitad del siglo XX. Editorial Lulu. (2016)

Ruesga Bono, J Intersecciones. La música en la cultura electro-digital. Sevilla: arte/facto. 
Sarmiento, J., Charles, D., Díaz Cuyás, J. \& Barber, L. (1996). Zaj. Madrid: Museo Nacional Centro de Arte Reina Sofía. (2004).

Steingress, G.. Flamenco postmoderno: entre tradición y heterodoxia: un diagnóstico sociomusicológico (escritos 1989-2006). Signatura Ediciones. (2007)

Taylor, M. J.. I'll be your mirror, reflect what you are: postmodern documentation and the downtown New York scene from 1975 to the present. RBM: A journal of rare books, manuscripts, and a cultural heritage, 3 (1), (2002), 32-51.

The Velvet Underground. I'll be your mirror. The Velvet Underground \& Nico. (1967)

UNESCO. http:/ / www.unesco.org/culture/ich/es/RL/el-flamenco-00363 (2010)

Viana, I. (15 de diciembre de 2010). Enrique Morente y sus modernuras. $A b c$.

Walther, I. F. Arte del siglo XX (vol. 2). Madrid: Taschen. (2012). 